\title{
THE INFLUENCE OF THE WAY OF PLANNING TEACHING CONTENT ON THE EFFECTIVENESS OF MASTERING SELF-DEFENCE TECHNIQUES
}

doi: 10.2478/v10038-012-0004-7

\author{
MIROSŁAW ZALECH
}

Józef Piłsudski University of Physical Education, Warszawa, Poland

\begin{abstract}
Introduction. The improvement of a learning process through transferring a skill already acquired to another one which is being learnt is one of the factors contributing to increasing the effectiveness of teaching. The aim of this study was to compare the effectiveness of teaching performed on the basis of two plans, i.e. a traditional (intuitive) one and a network one. Methods. A pedagogical experiment covering 13 weekly sessions of self-defence elements were taught. The control group was taught according to an algorithm developed in a traditional (intuitive) way, whereas the experimental group was taught according to a algorithm developed on the network model. After the sessions had been completed, five experts evaluated the acquisition level of three randomly selected elements. The results obtained by 32 men (average age $21.29 \pm 0.76$ years) from the experimental group and 32 men from the control group (average age $21.18 \pm 0.87$ years) were analysed statistically with the Student's $t$-test, two-way analysis of variance (ANOVA) and the Fisher post-hoc test. Results. The experts did not differ in evaluating both groups $(p<0.05)$. Moreover, no interactions were revealed $(p<0.05)$ between the method of planning the teaching programme and the experts who evaluated the acquisition level of the taught elements. The only significant difference between the experimental group and the control group was observed in the method of planning the teaching programme, according to which self-defence elements were taught $(p<0.01)$. Conclusions. The acquisition level of the taught self-defence elements according to the algorithm developed by basing it on the network model turned out to be significantly higher than in the case of those elements taught in the traditional (intuitive) planning process.
\end{abstract}

Key words: teaching programme, pedagogical experiment, traditional (intuitive) planning, network planning, acquisition of self-defence

\section{Introduction}

Progress, within the process of learning, depends on a number of factors which determine the speed, quality, durability and flexibility of acquiring motor skills. These determinants may be divided into two groups. The first one includes external conditionings which cover everything that exerts influence on a student. The other one consists of the individual, physical and mental capacities of every learner [1]. As far as external conditionings are concerned, one of the determinants is the planning of a teaching programme. To bring about the expected results in the form of acquiring new skills in the best possible way, the manner and scope of this activity ought to take into consideration, inter alia, the existing similarities between them. This makes it possible to use positive transfer, which occurs when material mastered in one context positively influences the course and the final result of learning other material in the same or different context [2, 3].

So far, research on transfer was concerned with various aspects of motor functioning of a human being $[4,5]$, including learning motor activities from different sports $[6,7]$ as well as within the same one [8]. The practical meaning of this research makes it possible to assume that implementing transfer into teaching will facilitate and improve the process of learning multi-element and complex activities such as self-defence. Most often, while conducting such sessions there occur time limitations and learners' expectations of fast progress. It may seem plausible to improve this process through making use of positive transfer. However, knowledge of the connections between the taught elements is indispensable. It is a hard and intricate task indeed. What is more, a traditional way of planning which draws upon the knowledge, intuition and experience of coaches is not very effective. Therefore, researchers are looking for better methods of optimising this process [9]. One of them is the critical path method (CPM) [10], which makes it possible to reflect the connections that occur between taught elements. The use of this method makes it possible to point out which activities, having been acquired in the teaching process, may be followed by the other ones as well as which activities may be taught simultaneously [11].

As such, the aim of the study was to compare the effectiveness of teaching self-defence elements according to two methods of planning a teaching programme, i.e. traditional (intuitive) planning and network planning. Experimental research was used to test whether the optimisation of a plan at introducing particular elements of self-defence, in the course of teaching, facilitated 
better acquisition. This would be confirmed by an evaluation of the elements taught to the subjects in the experimental group (using a teaching process based on the network method), which was expected to be marked higher than in the evaluation of the subjects from the control group (using a teaching process based on the traditional method). This hypothesis is based on the assumption that network planning, already tested in other areas including teaching, will contribute to an increase in the effectiveness of teaching self-defence elements.

\section{Material and methods}

Random male subjects were divided into two groups, i.e. a control one and an experimental one. Each of the groups consisted of four teams in which the training sessions were carried out. The selection methodology of the experiment and the selection criteria are presented in Figure 1.

In the pedagogical experiment, which lasted for 13 weeks, the subjects had to participate in 45 -minute weekly taekwondo sessions during which, apart from traditional techniques, elements of self-defence were

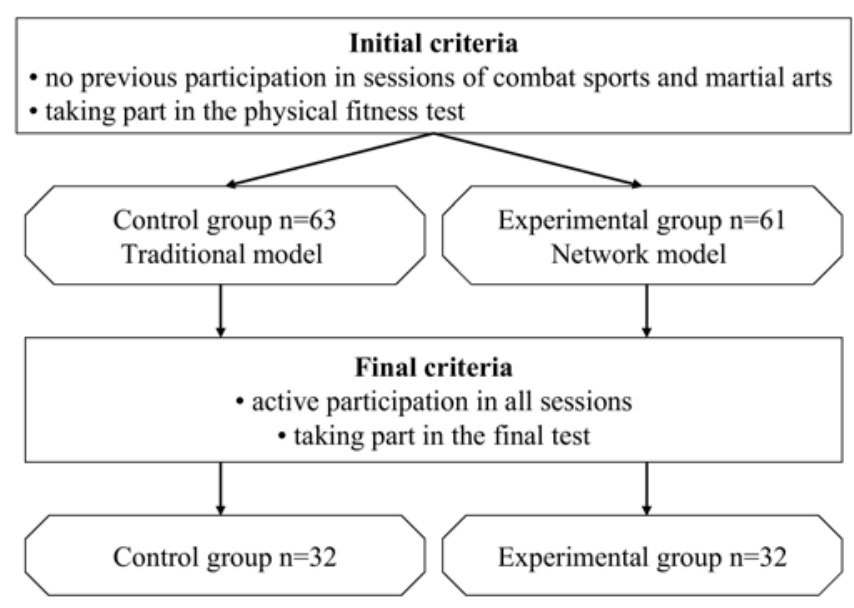

Figure 1. Methodology of subject selection
Table 1. List of taught self-defence elements

\begin{tabular}{cl}
\hline $\begin{array}{c}\text { Element } \\
\text { number }\end{array}$ & Element name \\
\hline 1 & Defence against a grab by one hand 1 \\
2 & Defence against one-hand grab by clothes 1 \\
3 & Defence against two-hand grab by clothes 1 \\
4 & Defence against hair grab \\
5 & Defence against two-hand rear choke \\
6 & Defence against a front grab by both hands 1 \\
7 & Defence against a rear grab by both hands \\
8 & Head release from a side grab \\
9 & Defence against a grab by one hand 2 \\
10 & Defence against two-hand grab by clothes 2 \\
11 & Defence against a front grab by both hands 2 \\
12 & Defence against a front grab by both hands 3 \\
13 & Defence against one-hand grab by clothes 2 \\
\hline
\end{tabular}

taught (Tab. 1). The amount of time devoted to mastering self-defence techniques during one session was between 5 and 10 minutes and depended on the number of elements taught as well as on circumstances that resulted from the teaching process, i.e. teacher-learner interactions.

The control groups' self-defence elements (Tab. 1) were taught according to an algorithm developed prior to the experiment which was based on observing taekwondo sessions (Tab. 2). The planning method used here may be called a traditional (intuitive) one because it mainly draws upon the skills and experience of coaches as well as on general programmes including requirements for particular degrees of advancement (gup, dan).

The first stage of developing the algorithm of methodological conduct for the experimental group was to find out the connections between the taught elements (Tab. 1). It consisted in defining which element or elements might be taught directly after acquiring a particular element or in parallel with it. The criterion applied for determining the order was the structure of techniques and their level of difficulty. Then those

Table 2. Algorithm of teaching self-defence elements* in the control groups

\begin{tabular}{|c|c|c|c|c|c|c|c|c|c|c|c|c|c|}
\hline Session number & I & II & III & IV & $\mathrm{V}$ & VI & VII & VIII & IX & $\mathrm{X}$ & $\mathrm{XI}$ & XII & XIII \\
\hline \multirow{7}{*}{$\begin{array}{l}\text { Elements taught } \\
\text { during particular sessions* }\end{array}$} & 1 & & \multirow{7}{*}{$\begin{array}{l}5 \\
8\end{array}$} & \multirow{7}{*}{-} & \multirow{7}{*}{$\begin{array}{r}3 \\
10 \\
13\end{array}$} & \multirow{7}{*}{$\begin{array}{r}4 \\
9 \\
11\end{array}$} & & \multirow{7}{*}{-} & & \multirow{7}{*}{7} & \multirow{7}{*}{8} & \multirow{7}{*}{-} & \multirow{7}{*}{-} \\
\hline & 3 & 2 & & & & & & & & & & & \\
\hline & 6 & 4 & & & & & 2 & & 2 & & & & \\
\hline & 9 & 7 & & & & & 3 & & 5 & & & & \\
\hline & 10 & 13 & & & & & 6 & & 13 & & & & \\
\hline & 11 & & & & & & 12 & & & & & & \\
\hline & 12 & & & & & & & & & & & & \\
\hline $\begin{array}{l}\text { Number of elements } \\
\text { taught during sessions }\end{array}$ & 7 & 4 & 2 & - & 3 & 3 & 4 & - & 3 & 1 & 1 & - & - \\
\hline
\end{tabular}

\footnotetext{
* elements are numbered consecutively as in Table 1.
} 


\section{HUMAN MOVEMENT}

M. Zalech, Influence of teaching on effectiveness of self-defence

Figure 2. Network model of teaching the self-defence elements

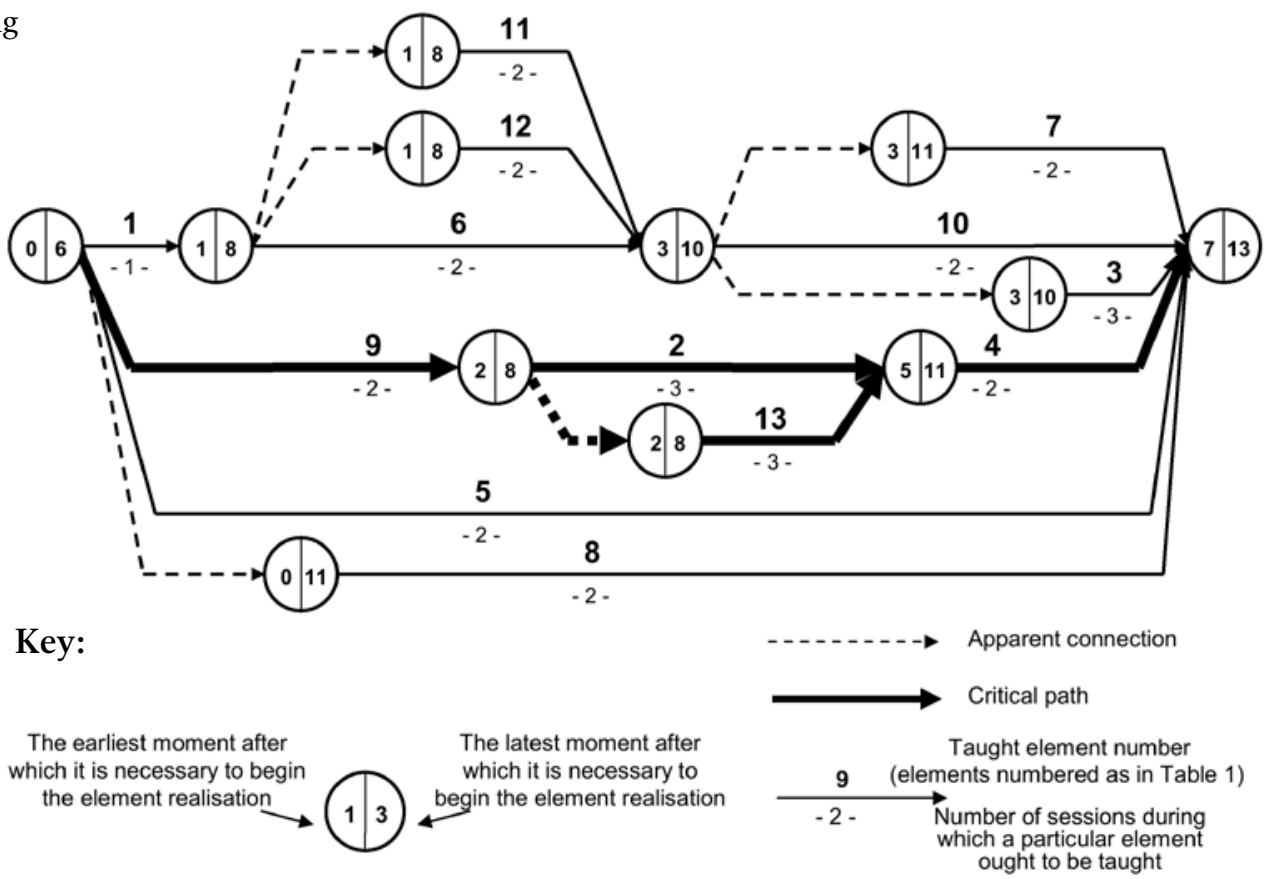

connections were projected with the use of the critical path method. The model constructed in this way was completed with the number of sessions necessary, according to experts, to master the particular elements by the examined group. This number was determined through consultations with three coaches with the $6^{\text {th }}$ dan and over 20 years of coaching experience. With the use of arrows, the created network determined the process of teaching particular elements and pointed to their order, i.e. those which may be taught simultaneously and those that can be implemented only after acquiring other elements. The arrows only point to a consequence; their length, shape and structure do not represent any kind of magnitude. Every activity (in this case the process of teaching a given element) is always determined by two occurrences (areas) indicating the beginning and the end of teaching. In order to embark upon teaching any element, it is indispensable to finish teaching all the preceding elements (Fig. 2). Based on this model the algorithm of teaching self-defence elements in the experimental group was developed (Tab. 3).
The algorithm was elaborated upon according to boundary conditions which are set by (1) the order of teaching elements, (2) the possible number of elements taught during the particular training sessions and (3) the time necessary to learn the elements. Within these criteria the elements of the programme were grouped so that their number at each session did not exceed five. The implementation of more elements in particular sessions (aimed at shortening the teaching time) would require, as the pilot studies revealed, more time devoted to their teaching at each training session.

The final stage of the study was to evaluate the level of the acquisition of the self-defence elements (i.e. the dependent variable) by the students. It was conducted by five experts with the $1^{\text {st }}$ dan in taekwondo. Three randomly selected self-defence elements were evaluated on a scale from 0 (not mastered) to 10 (mastered very well).

After the experiment the results of those who had met the required criteria were analysed. The average age of those subjects from the experimental group was

Table 3. Algorithm of teaching self-defence elements in the experimental groups

\begin{tabular}{|c|c|c|c|c|c|c|c|c|c|c|c|c|c|}
\hline Session number & I & II & III & IV & $\mathrm{V}$ & VI & VII & VIII & IX & $\mathrm{X}$ & XI & XII & XIII \\
\hline \multirow{5}{*}{$\begin{array}{l}\text { Elements taught } \\
\text { during particular sessions* }\end{array}$} & 1 & & 2 & 2 & 2 & & & \multirow{5}{*}{7} & \multirow{5}{*}{7} & \multirow{5}{*}{-} & \multirow{5}{*}{-} & \multirow{5}{*}{-} & \multirow{5}{*}{-} \\
\hline & 5 & 5 & 6 & 6 & 3 & 3 & 3 & & & & & & \\
\hline & 8 & 8 & 11 & 11 & & 4 & 4 & & & & & & \\
\hline & 9 & 9 & 12 & 12 & 10 & 10 & & & & & & & \\
\hline & & & 13 & 13 & 13 & & & & & & & & \\
\hline
\end{tabular}

Number of elements taught during sessions

$\begin{array}{lllllllll}4 & 3 & 5 & 5 & 4 & 3 & 2 & 1 & 1\end{array}$

* elements numbered as in Table 1. 
found to be 21.29 years $(\mathrm{SD} \pm 0.76)(N=32)$, while that of the control group was 21.18 years $(\mathrm{SD} \pm 0.87)$ $(N=32)$. The Student $t$-test was applied to find out if there were any differences between the groups in body mass, body height and the results of Pilicz general fitness test [12]. As far as the effectiveness of teaching is concerned, two-way analysis of variance (ANOVA) and the Fisher post-hoc test were used to evaluate it.

\section{Results}

The experimental and control groups did not differ significantly $(p<0.05)$ in body weight, body height and the results of the general fitness test which consisted of three parts: the standing long jump, $3 \mathrm{~kg}$ medicine ball throw and a zigzag run (Tab. 4).

The results of analysis of variance (ANOVA) revealed significant differences (effect Method; $F_{1 ; 310}=19.02$, $p<0.001$ ) between the average values of the evaluation variable depending on which method was used to plan the sequence of the taught elements. It means that the subjects learning with the use of the network method mastered the elements better than their counterparts from the control group. Furthermore, there occurred significant differences (effect Expert; $F_{4 ; 310}=$ $4.78, p<0.001$ ) between the experts in evaluating the elements taught. In addition, the influence of the method of planning the teaching programme on how well the self-defence elements were mastered turned out to be dependent on the expert (effect Method"Expert; $F_{4 ; 310}$ $=2.88, p<0.05$ ).

Revealing the differentiation between the average of the experts' evaluations required in-depth analysis in order to find out which of them differed from one another and if it was possible to indicate a homogeneous group. The results of the Fisher post-hoc test revealed significant differences between the average of evaluations by expert no. 1 and the other experts (Tab. 5). In this way

Table 4. Characteristics of the examined groups

\begin{tabular}{lcccc}
\hline Parameter & Group $^{*}$ & $\bar{x} \pm \mathrm{SD}$ & $t$ & $p^{* *}$ \\
\hline Body height & $\mathrm{E}$ & $179.81 \pm 6.59$ & 0.766 & 0.447 \\
$(\mathrm{~cm})$ & $\mathrm{C}$ & $180.97 \pm 5.43$ & & \\
\hline Body weight & $\mathrm{E}$ & $76.31 \pm 7.87$ & 0.692 & 0.492 \\
(kg) & $\mathrm{C}$ & $74.81 \pm 9.41$ & & \\
\hline Standing long & $\mathrm{E}$ & $221.81 \pm 23.25$ & 0.836 & 0.406 \\
jump (cm) & $\mathrm{C}$ & $216.97 \pm 23.10$ & & \\
\hline 3 kg medicine & $\mathrm{E}$ & $10.72 \pm 1.10$ & 1.478 & 0.144 \\
ball throw (m) & $\mathrm{C}$ & $10.23 \pm 1.52$ & & \\
\hline Zigzag run (s) & $\mathrm{E}$ & $22.62 \pm 1.75$ & 0.220 & 0.827 \\
\hline
\end{tabular}

* E - Experimental groups $(N=32)$; - Control groups $(N=32) ; * * p=$ level of statistical significance
Table 5. Unanimity of experts' evaluations.

Probabilities for the Fisher post-hoc test

\begin{tabular}{cccccc}
\hline Expert & 1 & 2 & 3 & 4 & 5 \\
\hline 1 & & 0.000 & 0.019 & 0.000 & 0.005 \\
2 & & & 0.240 & 0.674 & 0.502 \\
3 & & & & 0.111 & 0.614 \\
4 & & & & & 0.275 \\
5 & & & & & \\
\hline
\end{tabular}

Table 6. Two-way analysis of variance of the level of mastering the self-defence elements evaluated by the four experts

\begin{tabular}{lcccc}
\hline Source & SS & MS & $F(\mathrm{df})$ & $p^{*}$ \\
\hline Method & 7.91 & 7.91 & $7.46(1,248)$ & 0.007 \\
Expert & 3.32 & 1.11 & $1.05(3,248)$ & 0.373 \\
Method/Expert & 4.45 & 1.48 & $1.40(3,248)$ & 0.244 \\
\hline
\end{tabular}

SS - sum of squares, MS - mean square

$* p$ - level of statistical significance

a uniform group of experts was selected $(N=4)$ and their evaluations were once again analysed statistically.

No significant differences $(p<0.05)$ were revealed between the average of the experts' evaluations. There was also no interaction $(p<0.05)$ between the Method and Expert factors. Moreover, the results of the first analysis, in which the evaluations of all five experts were taken into consideration and where significant differences were observed between the groups as far as the method of planning the teaching programme was concerned $(p<0.01$ ), were confirmed (Tab. 6). The subjects taught according to the network plan mastered self-defence elements better $(\bar{x}=7.71 ; N=4)$ than the men from the control group $(\bar{x}=7.20 ; N=4)$, who were taught according to the traditional plan.

\section{Discussion}

All teaching plans ought to serve as a guide due to the fact that some events are unpredictable and cannot be planned [13]. As such, it is important to be able to make decisions interactively $[14,15]$. It is for this reason that network planning focuses only on systematising the main elements (techniques, actions) and does not interfere in the way sessions are conducted, leaving such issues up to the teacher. It is the teacher who, upon seeing their specific learners and the motor abilities they have, ought to select the proper auxiliary exercises [16]. The development of plans that combine the teaching content in both combat sports and martial arts with an application of the critical path method was the subject of modelling in a theoretical dimension $[17,18]$. However, no experimental research comparing the effectiveness of teaching in accordance with network and traditional planning has yet to be done. Only 
a few practical studies comparing the effectiveness of teaching based on various plans were carried out in swimming [19] and windsurfing [20]. The authors of those works stated that teaching according to the network plan was more effective than according to the traditional plan. This is confirmed by the results of this study. Male subjects who were learning self-defence techniques through network planning mastered them better than those who followed traditional planning $(p<0.01)$. Thus, the hypothesis stating that a teaching process based on the network plan is more effective than one conducted in a traditional way was confirmed. Despite being split, the teaching method presented in this study is based on a linear sequence set of similar movements taught in a linear set. They are combined with the use of the same element of the performed motor task, e.g. with a lever (in the model presented in Figure 2 these elements were marked with the following numbers: $2,9,4)$. A positive transfer of those elements was predictable since they represent the same type of movement structure. In addition, another factor affecting the level of mastering various motor tasks is the teaching algorithm itself [21].

The main factors distinguishing both methods were the order of implementing the new elements (actions, techniques) and their interval placement. In the network model, the order of taught techniques that made up the whole teaching programme were dependent on such assumed criteria as the structure of movements and their level of difficulty. Using this analogy as a basis makes it possible to transfer a part of the representation of one skill to another [22]. This is opposite to the traditional model, where knowledge, skills, intuition and the experience of coaches were the decisive factors. An important thing is that coaches pay less attention to long-term planning instead concentrate on current session preparation [23]. In comparison to the traditional method, the application of the network planning method was restricted by a complex structure of the model. This structure requires the use of a specialist to carry out an assessment that would make it possible to find out what connections occur between each of the taught elements according to assumed criteria. It is essential to be aware that a plan developed in this way is not an end-all solution. It is only an optimised solution based on the available information and it ought to be modified and improved during the course of its development.

The point of the majority of studies on transfer is, as Hoffman indicates [24], to confirm the elaborated assumptions of a number of theories on teaching and learning conducted by means of examinations carried out in laboratory conditions that are far from the realistic conditions in which these phenomena occur. The teaching approach suggested in this study goes beyond laboratory settings and shows a way in which, in natural conditions, it is possible to increase the effectiveness of instruction along with lowering the time and effort applied in the teaching process. It is worth highlighting that the optimisation of the sets of motor activities put forward in this study does not interfere with the teaching method used in each of the particular elements. A teacher can exert some influence both in the way of communicating [25] and teaching the elements [26]. The study shows that hitherto, the selectively analysed concepts of transfer [27], interference [28], reminiscence [29] and the strategy of teaching [30] can occur simultaneously in the process of teaching and learning.

\section{Conclusions}

1. The level of mastering self-defence elements taught according to an algorithm developed on the basis of the network model was significantly higher than in the case of elements taught according to the traditional (intuitive) plan.

2. Teaching based on the network model, which takes into consideration the structure of the taught elements and their level of difficulty, makes it possible to improve the learning process providing a positive transfer from elements previously mastered to those which are being learnt.

3. The development of teaching algorithms exempts coaches from having to analyse when to embark upon teaching a particular element and allows them to concentrate more effectively on how to teach it.

\section{References}

1. Arends R.J., Learning to Teach. McGraw Hill, New York 1994.

2. Perkins D.N., Salomon G., Transfer of learning. International Encyclopedia of Education. $2^{\text {nd }}$ ed., Pergamon Press, Oxford 1992.

3. Gallowey Ch.G., Psychology for learning and teaching. McGraw Hill Higher Education, New York 1976.

4. Inui N., Lateralization of bilateral transfer of visuomotor information in right-handers and left-handers. J Mot Behav, 2005, 37 (4), 275-283, doi: 10.3200/JMBR.37.4. 275-284.

5. Seidler R.D., Differential transfer processes in incremental visuomotor adaptation. Motor Control, 2005, 9 (1), 40-58.

6. Couzner B.N., The transfer of learning between tennis and table tennis skills. Australian Journal of Physical Education, 1974, 66, 5-8.

7. O’Keeffe S.L., Harrison A.J., Smyth P.J., Transfer or specificity? An applied investigation into the relationship between fundamental overarm throwing and related sport skills. Phys Educ Sport Pedagog, 2007, 12 (2), 89-102, doi: 10.1080/17408980701281995.

8. Weigelt C., Williams A.M., Wingrove T., Scott M.A., Transfer and motor skill learning in association football. Ergonomics, 2000, 43 (10), 1698-1707, doi: 10.1080/00 1401300750004104.

9. Kerzner H., Project management: a systems approach to planning, scheduling, and controlling. John Wiley \& Sons, Hoboken 2009. 
10. Taffler R., Using Operational Research. A practical introduction to quantitative methods in management. Prentice Hall International, London 1979.

11. Antill J.M., Woodhead R.W., Critical path method in construction practice. $4^{\text {th }}$ ed., John Wiley \& Sons, New York 1990.

12. Pilicz S., Measurement of overall physical fitness [in Polish]. Studia i Monografie AWF $w$ Warszawie, 1997, 65.

13. Carnahan R.S., The effects of teacher planning on classroom process. Technical Report No. 541. Wisconsin R \& D Center for Individualized Schooling, Madison 1980.

14. Schmidt R.A., Motor control and learning. Human Kinetics, Champaign 1988.

15. Marx R.W., Peterson P.L., The nature of teacher decision making. In: Joyce B.R., Brown C.C., Peck L. (eds.), Flexibility in teaching: An excursion into the nature of teaching and training. Longman, New York 1981, 236-255.

16. Jaczynowski L., Network models of motion teaching [in Polish]. SiT, Warszawa 1978.

17. Sterkowicz S., Spelak S., Optimisation of technical-tactical judo training plan of judokas aged 13-14. In: Sterkowicz S. (ed.), Professional activities of a coach and research problems in combat sports [in Polish]. Zeszyty Naukowe AWF $w$ Krakowie, 2001, 83, 166-178.

18. Sterkowicz S., Madejski E., ABC Hapkido [in Polish]. KASPER, Kraków 1999.

19. Gužalovskij A.A., Experimental fundamentals of the methods of network planning in the process of teaching swimming [in Russian]. Teoriâ i Praktika Fizičeskoj Kul'tury, 1974, 1, 49-52.

20. Zybko P., Jaczynowski L., Application of network planning to teaching windsurfing. Phys Educ Sport, 2008, 52, 5-10, doi: 10.2478/v10030-008-0002-x.

21. Giuffrida C.G., Shea J.B., Fairbrother J.T., Differential transfer benefits of increased practice for constant, blocked, and serial practice schedules. J Mot Behav, 2002,34(4),353-365, doi:10.1080/00222890209601953.

22. VanLehn K., Cognitive skill acquisition. Annu Rev Psychol, 1996, 47, 513-539, doi: 10.1146/annurev.psych.47.1.513.
23. Clark C.M., Yinger R., Teachers' thinking. In: Peterson P.L., Walberd H.J. (eds.), Research on teaching. McCutchan, Berkeley 1979, 231-263.

24. Hoffman S.J., Relevance, application, and the development of an unlikely theory. Quest, 1990, 42 (2), 143-160.

25. Dybińska E., Visual information communication in creation of mental programmes during teaching motor activities. Hum Mov, 2005, 6 (2), 85-92.

26. Duda H., Effects of programmed instructions on training efficiency in male and female football players. Phys Educ Sport, 2006, 50, 89-92.

27. Bebko J.M., Demark J.L., Im-Bolter N., MacKewn A., Transfer, control, and automatic processing in a complex motor task: an examination of bounce juggling. J Mot Behav, 2005, 37 (6), 465-474, doi: 10.3200/JMBR.37.6. 465-474.

28. Brady F., A theoretical and empirical review of the contextual interference effect and the learning of motor skills. Quest, 1998, 50 (3), 266-293.

29. Moulton C.-A.E., Dubrowski A., MacRae H., Graham B., Grober E., Reznick R., Teaching surgical skills: what kind of practice makes perfect? Ann Surg, 2006, 244 (3), 400409, doi: 10.1097/01.sla.0000234808.85789.6a.

30. Meaney K.S., Griffin L.K., Hart M.A., The effect of model similarity on girls' motor performance. J Teach Phys Educ, 2005, 24, 165-178.

Paper received by the Editors: February 11, 2011

Paper accepted for publication: August 17, 2011

Correspondence address

Mirosław Zalech

Akademia Wychowania Fizycznego

Józefa Piłsudskiego

ul. Akademicka 2

21-500 Biała Podlaska, Poland

e-mail: miroslaw.zalech@awf-bp.edu.pl 